\title{
Aspectos teóricos sobre o ensino de ciências por investigação
}

\author{
José Galúcio Campos ${ }^{1}$ \\ Daniel Richardson de Carvalho Sena ${ }^{2}$
}

\begin{abstract}
RESUMO
Este texto apresenta considerações teóricas sobre o ensino por investigação. Em atenção a diversidade de atribuição de significados a esta abordagem didática apresentamos duas possíveis delimitações: primeiramente sobre o tipo de investigação que se deve praticar, em segundo, sobre o tipo de problema que se deve investigar; tanto a primeira como a segunda apresentam-se no contexto da escola básica. Em seguida, propomos três bases epistemológicas que devem fundamentar o ensino de ciências por investigação.
\end{abstract}

PALAVRAS-CHAVE: Ensino de ciências. Ensino por investigação. Epistemologia.

Theoretical aspects of science inquiry-teaching

\begin{abstract}
This text presents theoretical results on inquiry-teaching. Considering the diversity of meaning attribution to this didactic approach, we present two possible delimitations: firstly about the type of investigation that should be practiced, secondly about the type of problem that should be investigated; both the first and second are presented in the context of the elementary school. In addition, we propose three epistemological bases that inquiry-teaching should underlie.
\end{abstract}

KEYWORDS: Science teaching. Inquiry-teaching. Epistemology.

\footnotetext{
1 Doutor. Instituto Federal do Amazonas, Manaus, Amazonas, Brasil. http://orcid.org/0000-0001-7790-0785. jose.campos@ifam.edu.br.

2 Mestre. Instituto Federal do Amazonas, Manaus, Amazonas, Brasil. https://orcid.org/0000-0002-6085-7650. daniel.sena@ifam.edu.br.
} 
Aspectos teóricos de la enseñanza de las ciencias por investigación

\begin{abstract}
RESUMEN
Este texto presenta resultados teóricos sobre la enseñanza por investigación. Teniendo en cuenta la diversidad de atribuciones de significado a este enfoque didáctico, presentamos dos posibles delimitaciones: en primer lugar, sobre el tipo de investigación que debe practicarse, en segundo lugar, sobre el tipo de problema que debe investigarse; Tanto el primero como el segundo se presentan en el contexto de la escuela primaria. A continuación, proponemos tres bases epistemológicas que deberían ser la base de la enseñanza de la ciencia mediante la investigación.
\end{abstract}

PALABRAS CLAVE: Enseñanza de las ciencias. Docencia por investigación. Epistemología.

\author{
$* * *$ \\ Todo conhecimento humano começou com intuições, passou \\ daí aos conceitos e terminou com ideias. \\ Immanuel Kant.
}

\title{
Introdução
}

Este texto tem o objetivo de apresentar elementos teóricos sobre a abordagem didática do ensino por investigação no que concerne à delimitação objetiva, bases epistemológicas e modelos pedagógicos. Estes elementos uma vez conhecidos podem bem conduzir a prática pedagógica do professor, em especial daqueles com pouca experiência e dos formandos que se encontram diante do estágio supervisionado.

É prática comum modelar o ensino de química, ciências biológicas no ensino médio - e de ciências naturais - no ensino fundamental - através do ensino por investigação. Adversamente, só de raro em raro vemos algum artigo sobre o ensino de física que lhe tenha recrutado. 
Respostas a tal observação não repousam neste presente texto, mas antes, cabe defender a seguinte tese de que não há como praticar atividades investigativas na escola básica sem que nós, os professores, tenhamos o controle teórico de suas bases epistemológicas e dos modelos pedagógicos que por meio delas podemos praticar.

Muitos entendem que organizar o ensino das ciências da natureza pela investigação consiste num misto de mimetizar o trabalho do cientista com alguma pedagogia construtivista. Respondemos que não. Como veremos, o ensino por investigação é plural e a deliberada redução às pedagogias construtivistas correspondem a falta de conhecimento técnico ou senso comum.

Dado o ocaso da atribuição de significados plural que inere ao ensino por investigação, há a necessidade de delimitá-lo. Neste presente ensaio delimitamo-lo por duas vias: a primeira analisando que tipo de investigação faz sentido praticar na escola básica; a segunda, especificando como devem ser os problemas utilizados pelos professores para pôr o aluno diante de investigações cujo fim não seja o desenvolvimento científico.

Pedagogicamente ensinar por investigação, ou modelar o ensino das ciências pela investigação, tem dois fins: reforçar conceitos ou desenvolver habilidades. Recentes pesquisas mostram que para segunda opção ele é mais eficiente que a primeira. Portanto, cabe ao professor saber que modelo pedagógico é mais indicado para cumprir este ou aquele fim.

É do nosso entendimento que sem conhecimento teórico para guiar nossa prática didática os processos de ensino podem resumir-se a tentativa e erro. Acreditamos que isso tem grande potencial para disparar um processo em cascata de degradação profissional, desestímulo discente, e acentuar os problemas no ensino das ciências.

Esperamos que com este ensaio consigamos ao menos mitigar estes problemas por meio dos elementos teóricos aqui contidos, e, esboçar uma reflexão sobre interessante abordagem didática que convém a este ensaio: o ensino por investigação. 


\section{Ensino por investigação}

Historicamente o ensino por investigação originou-se no início do século XX como crítica ao status quo educacional vigente; desde então, essa abordagem didática sofreu várias reformulações ante as ocorridas reformas educacionais, que por sua vez aconteceram como consequência de novos anseios político, econômico e social (TRÓPIA, 2011; RODRIGUES; BORGES, 2008; ZÔMPERO; LABURÚ, 2011).

Uma característica que inere às reformas curriculares ocorridas foi que, ora objetivo da educação científica voltava-se para formar o indivíduo por meio do desenvolvimento de suas capacidades intelectuais; ora priorizava a formação da coletividade através da resolução de problemas reais com apelo social (RODRIGUES; BORGES, 2008).

Uma outra característica observada foi que, na primeira metade do século XX, as reformas educacionais foram praticadas valendo-se da visão de ciência neutra; após a segunda metade do mesmo século, essas reformas propuseram-se a superar esta visão despretensiosa sobre como o desenvolvimento científico poderia acontecer à revelia da realidade circundante (TRÓPIA, 2011).

Ainda em atenção a superação da visão de ciência neutra, Campos (2018) observa da literatura que a educação científica passou a fomentar as seguintes dimensões; quais sejam: ensinar fatos da ciência, ensinar sobre ciências, e, ensinar a fazer ciências. A primeira consiste em ensinar leis e teorias científicas, a segunda trazia as dimensões social, política, econômica e filosófica - comum a qualquer atividade humana - para o ensino das ciências, e, por último, o fazer que partia da constatação imediata de que: para se produzir ciências usava-se o experimento, então para ensiná-la se deveria utilizá-lo também.

Conforme assinala Barrow (2006), John Dewey - importante filósofo do pragmatismo norte-americano - foi o precursor do ensino por 
investigação. Por conseguinte, é considerado, também, como um dos mais importantes teóricos da escola progressista.

Rodrigues e Borges (2008) apontam que uma das críticas mais contundentes feita por Dewey à educação jesuítica de sua época, foi que esta tinha as ciências naturais como uma coleção de informações acabadas, em vez de um método ou uma atitude mental capaz de transformar outras formas de pensamento.

Zômpero e Laburú (2011) observam que a pedagogia jesuítica enfatizava a memorização e a repetição; no entanto, Dewey defendia que o elemento mais importante para aprendizagem é a ação ou participação ativa do aluno. Essa ação, complementa Barrow (2006), aconteceria por meio de investigações de problemas científicos relevantes para o aluno, realizadas com o método científico.

De acordo com Trópia (2011), Dewey argumentava que por meio do método científico seríamos capazes de desenvolver o pensamento e a razão, educar a mente, aprender assuntos científicos, além de entender os processos inerentes à ciência. Assim, para Dewey, modelar o ensino das ciências através do método científico atendia a um só tempo, o aprender ciências, aprender sobre ciências e o fazer ciências.

As críticas de Dewey à escola clássica nos remetem a duas situações: primeira é a defesa de uma pedagogia centrada no aluno (CRATO, 2010); a segunda é a adição do aspecto pragmático-instrumentalista ao ensino das ciências como consequência do uso do método científico (ZÔMPERO; LABURÚ, 2011).

Todavia, apesar das ideias originais e inspiradoras da nova escola ou escola progressista - em especial as ideais de Dewey - terem recebido bastante atenção, não trouxeram as melhoras esperadas. Gaspar (2014) lembra que após anos de aplicação dessas ideais novas na educação não foi observado os acréscimos no rendimento escolar, e, nem a diminuição da evasão estudantil. 
As pedagogias centradas no aluno costumam minimizar a importância do currículo escolar e investir em desenvolvimento de projetos que atendem problemas que ao aluno convém - seja individualmente ou em grupo. Mas não há como deixar de notar que esta prática pedagógica de caráter libertador e emancipatório comprometeu sim, a longo prazo, a universalidade do conhecimento científico, tornando-o em um acumulado de situações particulares (CRATO, 2010), restando maiores dificuldades a tão almejada alfabetização científica (SASSERON, 2015).

Podemos entender, portanto, que o ensino por investigação é uma abordagem didática que modela o ensino das ciências através de atividades práticas de acordo com as etapas do método científico.

Com efeito, emerge disto, uma situação bastante delicada, pois, afinal, usa-se do método científico para produzir conhecimento; este é o objetivo da investigação científica. Logo, como transpor essa realidade para contexto escolar? Que investigação se pratica no ensino por investigação?

Sobre estas questões nos debruçamos a respondê-las nas próximas seções.

\section{Investigação na escola básica}

O termo investigação, embutido no ensino por investigação, vem do Inglês inquiry que é, a um só tempo, ponto de convergência e divergência entre toda a gente envolvida com a educação científica. Na tradição anglosaxônica temos o inquiry-teaching e o teaching as inquiry; sendo que, no primeiro caso, a investigação é vista como uma disciplina curricular, ao passo que no segundo, a investigação é um recurso didático ou pedagógico (BARROW, 2006; RODRIGUES; BORGES, 2008; TRÓPIA, 2011; ZÔMPERO; LABURÚ, 2011).

Ante o exposto, portanto, é possível estabelecer com maior precisão, o que se entende por investigação no contexto da escola básica, assim como nos anos iniciais do ensino de graduação. Volta-se nossa preocupação para 
os ciclos básicos da educação, pois o objetivo é o ensino-aprendizagem, a preparação intelectual do aluno; mas não a produção de conhecimento científico.

Mas ora, se vamos fazer uma investigação, e não vamos produzir conhecimento, como deve ser essa tal investigação? Quais os pressupostos didáticos-pedagógicos da investigação escolar? Constatamos que a estas questões nos foge aquela univocidade tranquila que serviria de apoio para que possamos respondê-las.

Diante deste intento, autores como Barrow (2006), e, Rodrigues e Borges (2008) notaram que só foi possível começar a respondê-las após a década de 1980 devido ao grande volume de publicação sobre o ensino por investigação.

O método utilizado pelos autores que intentaram fazê-lo foi observar os traços convergentes entre as diversas publicações sobre o tema. Particularizando para o contexto deste presente manuscrito, três trabalhos foram significativos para que fizéssemos tal delimitação: o relatório do NCR (2000), os artigos de Abd-El-Khalick et al. (2004) e de Ferreira, Hartwig e Oliveira (2010).

Ferreira, Hartwig e Oliveira (2010) ressaltam que estamos diante de uma atividade de investigação se respondemos positivamente a cada uma das questões que segue: a atividade didática A1) - está voltada para a solução de uma questão-problema?; A2) - leva o aluno a formular hipóteses?; A3) - permite a coleta e análise de dados pelos alunos?; A4) - encoraja os alunos a formular explicações por meio de evidências?; A5) - permite a comparação das soluções propostas com várias outras?; e, A6) - propicia a discussão de resultados com os demais colegas e o professor?

Desse modo constatamos o seguinte: em primeiro lugar, que as etapas do trabalho do cientista, quando transpostas ao contexto escolar, tornam-se pressupostos didático-pedagógicos; em segundo lugar - como veremos mais a frente -, nem toda atividade investigativa no contexto escolar precisa atender a todas essas 6 perguntas a um só tempo. 
Com efeito, cada um desses pontos assinalados por Ferreira, Hartwig e Oliveira (2010) receberá o acento maior dependendo do direcionamento dado pelo professor. Para ilustrar, Kasseboehmer e Ferreira (2013) puseram o acento no desenvolvimento de hipóteses; Borges e Rodrigues (2004) no planejamento de experimentos investigativos; outros como Kanari e Millar (2004) enfatizaram a coleta e a interpretação de dados experimentais; Sasseron (2015) ressaltou somente a argumentação.

Concluímos assim que para caracterizar uma investigação - ante preocupações de ordem pedagógica - basta que uma das questões indicadas por Ferreira, Hartwig e Oliveira (2010) seja atendida.

Passamos, agora, para considerações feitas por Abd-El-Khalick et al. (2004). O que eles apontam, de fato, são dicotomias do tipo: ensinar por investigação versus ensinar como investigação; saber científico versus fazer científico; formação coletiva versus formação individual. Vejamos, em seguida, estas dicotomias: B1) - aprender ciências versus aprender sobre ciências; B2) - ciência como busca pela verdade versus ciência como atividade de resolução de problemas; B3) - levantar e responder questões versus propor e revisar modelos; B4) - ciência como atividade cognitiva versus ciência como atividade social; B5) - demonstração de conceitos versus investigação sobre como sabemos algo; B6) - ciência hipotético-dedutiva versus modelo baseado em ciência; B7) - ciências para testar conhecimentos versus ciência para descoberta.

Como resta observar, estas dicotomias dizem respeito ao que foi o ensino das ciências em detrimento dos anseios das novas pedagogias (CAMPOS, 2018). Cabe, ademais, tomar nota de que a investigação, neste referido contexto de dicotomias, está para além de ensinar conceitos ou desenvolver habilidades, está, pois, para elucidar os processos científicos.

Voltando-se a atenção, agora, para o relatório do NCR (2000), temos as seguintes considerações para que uma atividade seja investigativa: $\mathrm{C} 1)$ possibilitar o engajamento do aluno; C2) - priorizar a busca por evidências; 
C3) - explicar por meio de evidências; C4) - desenvolver a argumentação do aluno através da exposição de conclusões.

Fazendo juízo a respeito dos critérios do NCR, vemos claramente, o quanto se usa a investigação, - ao modo do cientista, - para modelar o ensino das ciências com intuito de desenvolver habilidades de investigação e cognitivas.

Ante o exposto, chegamos à conclusão de que todas os achados desses autores são imprescindíveis para classificar uma atividade didática como investigação. À estas lhe pomos apenas um único acréscimo: que toda atividade investigativa deve começar com uma situação-problema contextualizada como observado por Carvalho (2014).

Particularmente, defendemos os seguintes três pontos para classificar uma atividade como investigativa: D1) - começar por uma situaçãoproblema, não trivial, que deve ser contextualizada, obrigatoriamente; D2) ter o objetivo de reduzir a distância entre o conhecimento de referência e o ensinado nas escolas por meio de atividades práticas - excluindo-se, tentativa e erro; D3) - estimular a cognição do aluno ao longo da aquisição da aprendizagem científica.

Esses pontos não existem separadamente ante uma atividade de investigação. Não são pressupostos que podemos pôr o acento em algum individualmente; assim ou temos os três ou não teremos uma atividade de investigação. Contudo, ainda assim, não podemos extrapolá-los e sugerir uma definição, pois afinal, termos como contextualizar, atividades práticas além de aproximar a ciência escolar daquela do cientista são plurais e de entendimento complexo.

Nos interessa, entretanto, deixar claro que, apesar de não haver uma definição unívoca do ensino por investigação, isso não deve ser visto como um ponto de fragilidade a ponto mesmo de desistirmos de usá-lo, outrossim, que o professor pode usá-lo em seu favor. Todavia, para que tal empresa se realize, é necessário que o professor - ao construir seu planejamento e sua 
prática docente - tenha o controle teórico sobre as possibilidades de ensinar por investigação.

Logo, como vimos, uma investigação despretensiosa frente a produção de conhecimento, na escola básica, faz-se mimetizando as etapas de trabalho do cientista, ou, tomando apenas algumas destas etapas, atendendo a um só tempo a nossa proposição contida nos itens D's supra referidos. Desse modo, reforçamos a aprendizagem de conceitos e, desenvolvemos habilidades práticas e cognitivas dependendo ao que convier a atividade didática em questão.

\section{Problemas científicos na escola básica}

Falta-nos, entretanto, esclarecer um ponto crucial com grande estreitamento com o tipo de investigação que praticamos no contexto da escola básica. Partindo do princípio de que toda investigação se presta a resolver um problema, emerge a questão: que tipo de problemas são subjacentes ao ensino por investigação? Mas, há, entretanto, uma questão precedente e mais fundamental; qual seja: o que é um problema?

Willingham (2011, p. 24) diz que temos um problema quando perdemos a capacidade de solucioná-lo por automatismos, ou seja, não temos uma solução armazenada na memória. Observe, por exemplo, que ninguém reflete ou raciocina quando se levanta da cadeira para beber água; um matemático experiente não vacila ao ser perguntado quanto é $2 \times 2$; um físico teórico enuncia os postulados da relatividade tranquilamente.

Ainda conforme a explicação do mesmo autor, quando estamos diante de uma situação nova, recorremos, num primeiro instante, a memória de trabalho - entendida como a consciência do indivíduo, - se ainda assim não conseguirmos entender o que está acontecendo, recrutamos, num segundo momento, a memória de longo prazo; se após vasculhar a memória de longo prazo não conseguimos dar conta do que acontece ao nosso redor; tomamos consciência de que temos um problema. 
Seguindo a mesma linha de raciocínio, Sternberg e Sternberg (2016, p. 380), atestam que a característica do problema é a falta de conhecimento - com precisão ou em aproximação - que temos para resolvê-lo. Isto explica o porquê um estudante do ensino médio tem dificuldade para conceituar a velocidade média de um móvel como a rapidez da mudança de sua posição no tempo (NUSSENZVEIG, 2013).

Portanto, um problema não pode ser visto, apenas, pelo grau de dificuldade consensual para resolvê-lo; mas, também, pelo nível de conhecimento de quem se lança nesta tarefa.

Este é o ponto que pomos em relevo nesta seção: um problema não é representado do mesmo modo por todos. Um físico experiente representa um problema de cinemática de forma mais elaborada que um físico não experiente. Para o perito, o espaço de solução do problema - que é o conjunto de soluções possíveis - é maior que para o neófito; isto é um fato bem conhecido cientificamente (WILLINGHAM, 2011; STERNBERG; STERNBERG, 2016).

Sternberg e Sternberg (2016) indicam 7 etapas no ciclo de resolução de problemas; quais sejam: identificação, definição, formulação de estratégia, organização de informações, alocação de recursos, monitoramento e avaliação. Entretanto, o que nos interessa agora não são as etapas; mas as classes em que podemos dispô-los individualmente.

Sendo assim, os problemas classificam-se entre estruturados e os mal estruturados. Este, pois, não tem um caminho - um algoritmo - bem definido para solução; aquele, tem. Há, contudo, uma terceira classe que muito nos interessa: os problemas em movimento.

Sternberg e Sternberg (2016, p. 383) definem o problema em movimento como um problema estruturado cujo sujeito tem pouco conhecimento específico sobre ele. Em nossa opinião, é deste tipo de problema que o professor da escola básica deve se utilizar quando pretende modelar o ensino de ciências por meio da investigação. 
Com efeito, os problemas no ensino por investigação devem ser de tal sorte que os alunos não consigam resolvê-los por meios de automatismos como em geral acontece com os problemas estruturados -, mas que, também, não lhes sejam propostos problemas além das suas capacidades intelectuais - como os mal estruturados.

É importante, no contexto da escola básica, que tenhamos em conta que não se ensina a resolver problemas inéditos, mas sim, problemas com soluções perfeitamente conhecidas (CARVALHO, 2014, p. 103).

Há de se observar que num primeiro instante, para o aluno, antes da explicação do professor, estas soluções ainda não lhes são conhecidas, porquanto torna-se possível transformar um exercício, em um problema em movimento. Para tanto, deve-se colocar o aluno diante de situações cujo conteúdo curricular ainda não tenha sido trabalhado adequadamente. Acreditamos, pois, que nestas condições, conseguimos equilibrar a um só tempo, exigência e apoio.

Porquanto o exposto, delimitamos o que vem a ser o ensino por investigação em uma segunda aproximação: este é uma abordagem didática que modela o ensino das ciências por meio de atividades práticas subjacentes à atividade do cientista, usando-se, por sua vez, problemas (em movimento) contextualizados com soluções bem conhecidas, pelo professor.

$\mathrm{Na}$ seção seguinte, apresentamos as possíveis bases epistemológicas capazes de sustentar o ensino por investigação.

\section{Bases epistemológicas}

Apresentamos três bases epistemológicas possíveis que fundamentam às atividades pedagógicas, em geral; quais sejam: o empirismo, o apriorismo e o construtivismo. O empirismo ainda fundamenta muitas atividades didáticas, o apriorismo também, apesar poucos darem-se conta disso. Ademais ambos são entendidos como epistemologias clássicas cujo construtivismo se predispôs a superar (TERRIBILE, 2019). 


\section{a) - Empirismo}

A palavra empirismo deriva do grego empeiria, que significa experiência. Em teoria do conhecimento, o empirismo constitui um dos diversos pontos de vista que investigam o conhecimento humano.

Segundo Abbagnano (1999, p. 326) o empirismo consiste numa doutrina filosófica para qual a experiência é o critério ou norma da verdade. Ainda segundo o mesmo autor, a palavra experiência caracteriza-se pela negação do caráter absoluto da verdade e pelo reconhecimento que todo fato pode e deve ser posto à prova, portanto, eventualmente poderá ser modificado, corrigido ou abandonado (ABBAGNANO, 1999, p. 548 - 549).

O empirismo, portanto, se contrapõe ao racionalismo, pois, segundo essa perspectiva, o espírito humano nasce vazio de conteúdo, ele é uma tabula rasa que deverá ser preenchida pelos caracteres da experiência. É preciso ressaltar, todavia, que o empirismo não nega o valor nem se opõe à razão, a não ser quando a razão busca estabelecer verdades universais e necessárias sem critérios de avaliação.

As origens do empirismo remontam à antiguidade. Conforme Hessen (2000, p. 56) as concepções empiristas podem ser identificadas primeiramente nos sofistas e depois nos estoicos e epicuristas. Mas é na filosofia inglesa dos séculos XVII e XVIII, que essa corrente alcançará um desenvolvimento sistemático, destacando-se os pensadores Francis Bacon (1561 - 1626), John Locke (1632 - 1740) e David Hume (1711 - 1776).

Sob a influência do espírito de seu tempo, Bacon defendeu o emprego da ciência a serviço do progresso, compreendendo a importância do conhecimento e enfatizando que "saber é poder". Tal afirmação corrobora com a ideia de que o controle do homem sobre a natureza poderia facilitar a vida humana.

Para Bacon existia a necessidade da aplicação da experiência na construção de um conhecimento seguro, mediante um método preciso. Tal 
método consiste na indução, um processo que parte da análise de dados particulares tendo em vista a obtenção de generalizações.

Sobre o método proposto, Bacon (1988, p. 16) declara que existiriam apenas dois caminhos para a investigação da verdade: passar das sensações e das coisas particulares aos axiomas mais gerais; e recolher os axiomas dos dados dos sentidos e particulares, ascendendo contínua e gradualmente até alcançar os princípios da máxima generalidade.

O método indutivo desenvolvido por Bacon se mostra em sintonia com as ciências experimentais, onde o ponto de partida e de chegada está na experiência.

Seguindo a tradição inglesa, John Locke elabora uma teoria do conhecimento numa base empírica, que tenciona saber qual é o limite do conhecimento humano. A investigação de Locke tem como ponto de partida a origem das ideias na mente humana. De acordo com essa investigação, as ideias teriam duas possíveis fontes: a sensação e a reflexão.

Para Locke, a consciência humana é uma folha em branco que deverá ser preenchida com os dados da experiência. Hessen (2000, p. 56) explica que há uma experiência externa, a sensação, e outra interna, a reflexão. O conteúdo das experiências são ideias ou representações, algumas simples, outras complexas, formadas a partir das ideias simples. Às essas ideias pertencem as qualidades sensíveis dos objetos. Já uma ideia complexa seria, por exemplo, uma ideia de essência ou substância. Para Locke, nesse processo o pensamento não acrescenta nada de novo, apenas põe os dados da experiência em conexão uns com os outros.

A origem do conhecimento, portanto, é rigorosamente empirista. Entretanto, em relação à validade lógica, existem verdades que possuem validade universal que não dependem da experiência, como as verdades da matemática.

David Hume desenvolve sua teoria empirista partindo do pensamento de Locke. Hume (1984, p. 138) afirma a existência de dois ramos as impressões e as ideias. As impressões consistem nas percepções ou 
sensações mais fortes, que ocorre quando se vê, se toca ou se ouve; já as ideias seriam as representações menos nítidas, surgidas a partir das impressões originárias. Para Hume todas as ideias se originam de impressões e nunca o contrário. Para cada ideia deve existir alguma impressão, ou seja, todos os conhecimentos devem partir de algo dado pelos sentidos.

Hessen (2000, p. 59) observa que o grande mérito do empirismo para a investigação sobre o problema gnosiológico reside na oposição frente à negligência dos inatistas/racionalistas em relação a importância do papel da experiência do conhecimento. Todavia, ao fazer da experiência a única fonte do conhecimento, o empirismo troca um extremo pelo outro.

\section{b) - Apriorismo kantiano}

A palavra a priori significa literalmente aquilo que é anterior à experiência. Nesse sentido, o apriorismo caracteriza-se como uma doutrina que atribui autoridade aos conhecimentos e/ou conceitos que independem da experiência ou da prática.

$\mathrm{Na}$ tradição filosófica ocidental o apriorismo está ligado ao pensamento do filosofo alemão Immanuel Kant (1724 - 1804). De acordo com Hessen (2000), Kant fundou o apriorismo ante a tentativa de mediar os pressupostos do racionalismo de Leibniz e Wolf, e, do empirismo de Hume. Para o filósofo de Königsberg a matéria do conhecimento vem da experiência, enquanto a forma procede do pensamento.

Sob influência do filosofo escocês David Hume, Kant pôs em dúvida a capacidade humana de se atingir certezas (absolutas). Assim edificou o projeto da Crítica, uma criteriosa análise do conhecimento humano, tendo em vista a determinação do uso legítimo da razão.

Nas palavras de Kant (1994, p. 5) esse projeto significava a construção de um tribunal capaz de assegurar as pretensões legítimas da razão e de condenar todas as suas pretensões infundadas. 
Segundo Kant, a estrutura cognitiva humana, por meio de informações dadas pelos sentidos se sujeita a uma atividade conceitual a priori do entendimento, porém, seu uso legítimo restringe-se ao que pode ser intuído sensorialmente. Desse modo, qualquer intento ou aplicação fora deste limite sensível será sempre ilícito.

Kant (1983) afirma que existem duas vias do conhecimento humano: a sensibilidade e o entendimento. Pela primeira os objetos nos são dados, pela segunda, são pensados. O ponto de partida para a análise do conhecimento humano é a faculdade chamada de sensibilidade - onde corre a captação passiva dos objetos por meio dos sentidos -, analisada na Estética Transcendental, primeira parte da Crítica da Razão Pura.

$\mathrm{Na}$ sensibilidade existem duas formas de intuições puras e fundamentais à intuição sensível: o espaço e o tempo. Kant as chama de intuições puras, pois apesar de constituírem condições da sensibilidade, não estão no mundo, mas fazem parte da estrutura cognitiva humana. Espaço e tempo são condições para o conhecimento humano: o espaço é a forma da percepção externa e o tempo é a formada percepção interna.

Todavia, apenas por meio das formas a priori da sensibilidade não é possível a construção de qualquer conhecimento. É necessário que os dados intuídos sejam sintetizados por outra faculdade. Essa outra parte da estrutura cognitiva humana é o entendimento, que tem origem no intelecto. A sensibilidade fornece os objetos, enquanto o entendimento pensa-os através dos conceitos, ações do pensamento puro.

Na Lógica Transcendental, segunda parte da Crítica da Razão Pura, Kant descreve o processo de pensar as intuições por meio das formas a priori do entendimento, as categorias.

As categorias do entendimento são doze, divididas em quatro grupos de três: Categorias de Quantidade (Unidade, Pluralidade e Totalidade); Categorias de Qualidade (Realidade, Negação e Limitação); Categorias de Relação (Inerência e Substância, Causalidade e dependência e Comunidade) 
e Categorias de Modalidade (Possibilidade/Impossibilidade, Existência/Não Ser e Necessidade/Contingência).

O espaço e o tempo se aplicam em relação ao objeto dado a intuição de forma diferente dos conceitos. Devido apenas ser possível algo se dar por meio das intuições espaço temporais, só se perceberá algo de maneira especializada, por conseguinte, tal processo também só ocorrerá no tempo, de maneira simultânea ou sucessiva. O entendimento, por sua vez, não possui nenhuma ligação com os objetos da intuição. Então como irá aplicarse a eles? Kant explica que para um objeto fazer parte da experiência ele não carece apenas ser intuído, mas pensado. Enquanto dados à intuição os objetos são apenas fenômenos. Para intuir os objetos, as categorias não são necessárias, mas são imprescindíveis para pensá-los.

A estrutura cognitiva humana, por meio de informações dadas pelos sentidos se sujeita a uma atividade conceitual a priori do entendimento, sendo que, seu uso legítimo limita-se ao que pode ser intuído sensorialmente. Tudo que o entendimento realiza terá como finalidade o uso empírico, isto é, o conhecimento sempre será fenomênico.

De acordo com Kant (1983, p. 155), O entendimento apenas poderá fazer um uso empírico e jamais um uso transcendental dos seus princípios a priori ou de todos os seus conceitos. Esse sentido, o uso transcendental de um conceito, em qualquer princípio, incide no fato de ser reportado a coisas em geral e em si mesmas; já o uso empírico consiste em ser referido meramente a fenômenos, ou seja, aos objetos de uma experiência possível.

Percebe-se que na filosofia especulativa kantiana o sujeito é a autoridade na construção do conhecimento. Na teoria do conhecimento esse posicionamento é chamado de idealismo transcendental, pois o objeto é determinado a priori pela própria natureza da faculdade de conhecer humana, porém, sempre reportado aos dados intuídos pela experiência. Conforme Kant (1983, p. 13) com esse posicionamento pode-se explicar a possibilidade de um conhecimento a priori, além de prover de provas 
satisfatórias as leis que não se aparecem a priori na natureza, enquanto conjunto dos objetos da experiência.

Essa breve exposição sobre os fundamentos da filosofia especulativa kantiana demonstra que o apriorismo considera como fonte de conhecimento tanto a experiência como a razão e que nosso conhecimento possui elementos de natureza formal, a priori, constituintes de nossa estrutura cognitiva.

\section{c) - Construtivismo}

Há de observar que construtivismo é um termo usado indiscriminadamente na filosofia, na psicologia e na pedagogia. E disto emerge uma série de interpretações equivocadas sobre seus fundamentos e alcance (CASTAÑON, 2015). Não cabe aqui neste presente ensaio discutir sobre todas as possibilidades de construtivismos aceitos pela academia, outrossim, delimitar o construtivismo piagetiano.

De modo geral, o construtivismo é uma teoria epistemológica que nega o conhecimento como algo posto/pronto, seja ao modo do empirismo admitindo que o conhecimento está determinado no objeto, ou, ao modo do apriorismo, admitindo que já o temos internalizado em nossas estruturas mentais (BECKER, 2003; CASTAÑON, 2015).

O construtivismo piagetiano é um caminho do meio, tomando o que há de melhor no empirismo e no apriorismo com intuito de superar as dificuldades inerentes as epistemologias tradicionais que não explicam satisfatoriamente como se dá o conhecimento (BECKER, 2003; CASTAÑON, 2015; TERRIBILE, 2019).

De fato, para Piaget, o conhecimento é um construto advindo da relação dialética entre sujeito e objeto (BECKER, 2003). Japiassú e Marcondes (2006, p. 55) dizem a este respeito que toda teoria construtivista tem a prerrogativa de que o sujeito caminha em direção ao conhecimento da realidade (do real) por meio da razão; nisto vemos o aspecto realista das teorias construtivistas como bem ressaltado por Castañon (2015). 
Para o construtivismo piagetiano, o conhecimento é construído pelo sujeito ativo em atenção aos dados da experiência; nem sujeito e nem experiência se impõe individualmente (BECKER, 2003).

A não imposição do sujeito advém da constatação de que nossas teorias ou hipóteses (razão) sobre a realidade podem estar em desacordo com a experiência (empiria). Do mesmo modo, é necessário um sujeito ativo para organizar os dados da experiência, dado que esta não se impõe organicamente no sujeito (TERRIBILE, 2019).

Disto retira-se duas conclusões: (i) de que construtivismo não é sinônimo de construção da realidade, pois afinal, existe aspectos da realidade (objeto) que não se adequam as nossas expectativas teóricas; (ii) o conhecimento não é uma cópia da realidade circundante, mas antes uma representação simplificada da realidade - cópia esta forjada pelo sujeito que pode ser falseada de tempos em tempos (CASTAÑON, 2015). Assim, vemos que o construtivismo admite tanto um realismo ontológico quanto epistemológico. Este significa que é possível conhecer os objetos independente da mente humana; ao passo que àquele, quer dizer que os objetos existem independentemente da consciência do sujeito (CASTAÑON, 2015).

Conforme Piaget, existem dois processos pelos quais o sujeito cria suas representações da realidade adquirindo, consequentemente, o conhecimento; quais sejam: assimilação e acomodação. A assimilação é o entendimento e a organização dos dados experiência pelos esquemas mentais (a priori) contidos no sujeito. A acomodação surge quando não conseguimos enquadrar os dados da experiência nestes esquemas mentais prévios resultando, portanto, na sua modificação ou, até mesmo, na construção de novos esquemas mentais (BECKER, 2003).

Neste último aspecto repousa uma diferenciação importante entre o apriorismo kantiano do piagetiano. Para Piaget, as estruturas mentais, ou, esquemas, modificam-se ou são produzidas pelo sujeito; daí a importância, também, atribuída à experiência por Piaget (BECKER, 2003; CASTAÑON, 
2015; TERRIBILE, 2019). Por seu turno, para Kant, como vemos em sua Crítica da Razão Pura, as suas categorias do entendimento são estáticas, não se modificam ao longo da vida do sujeito (KANT, 1983).

Ainda em atenção aos processos de assimilação e acomodação, Piaget classifica o conhecimento de dois modos tomando-o, ora como fato ou conteúdo; ora como estrutura. Como fato, temos as leis da física; como estrutura, temos as ações ou a coordenações das ações realizadas pelo sujeito ante o ato de investigação (BECKER, 2003; TERRIBILE, 2019).

Como já antecipamos, existem vários construtivismos, entretanto, o que todos têm em comum: a ação de um sujeito ante o entendimento do mundo (objeto). Acrescenta-se a isto a observação de que, já em uma primeira análise, a ação do sujeito já é, em si mesmo, um criticismo, pois o objeto não impõe sua representação sob o sujeito, mas antes é o contrário disto: o sujeito cria as representações do objeto através das formas da sensibilidade e das categorias do entendimento que encontram-se em sua mente, a priori ou construídos por ele (CASTAÑON, 2015; KANT, 1983).

\section{Modelos pedagógicos e metodologias de atividades investigativas}

$\mathrm{Na}$ seção anterior constam três teorias epistemológicas que dirigem nossa prática didática. Haja vista que nossa prática materializa-se em metodologias de ensino, estas, por sua vez, também encontram repouso nas bases epistemológicas supra referidas.

O empirismo fundamenta o modelo de ensino diretivo - mas conhecido como tradicional - sendo aquele em que o professor ensina por meio do testemunho. Logo, o aluno aprende por meio dos sentidos: ouvindo o professor falar, vendo-o escrever no quadro branco de modo a copiá-lo, e, usando o tato e o olfato em aulas de laboratório, por exemplo (BECKER, 2003). Em suma, o conhecimento, a aprendizagem é um movimento de fora para dentro do sujeito (SANTOS, 2013) 
O apriorismo assume que o conhecimento já está disposto na estrutura genética do sujeito cabendo ao professor, apenas, trazê-lo à superfície, donde emerge a figura do professor facilitador. Este modelo de aprendizagem é não-diretivo, e quando visto de si mesmo, é muito radical, pois basicamente exclui a figura do professor mediador; na verdade não aceitando mediações de quem quer que seja (BECKER, 2003). No apriorismo, vemos claramente, que a aprendizagem é um movimento de dentro do sujeito para fora.

O construtivismo, por seu turno, legitima o modelo dialogal de ensinoaprendizagem (SANTOS, 2013; BECKER, 2003). A aquisição de conhecimento, de novas aprendizagens, está no processo dialético professoraluno. As atividades escolares são tomadas, sempre, como uma prática colaborativa.

Ocorre que modelar o ensino de ciências pela investigação tem várias possibilidades metodológicas; quais sejam: as questões abertas, os problemas abertos e o laboratório aberto, só para citar algumas (CARVALHO, 2014). O ponto que nos convém aqui não é a conceituação de cada uma delas, mas antes, de pontuar que cada uma pode ser praticada a diferentes bases epistemológicas, consequentemente, a diferentes modelos pedagógicos.

Campos (2018) apresenta resultados de uma pesquisa realizada com alunos do ensino médio donde trabalhou com laboratório aberto e questões abertas de modo mais estruturado do que vemos de costume na literatura especializada. Uma vez que a prática didática seja mais estruturada significa que aproxima-se do modelo diretivo de ensino.

Carvalho (2014) ressalta que o preparo para as atividades investigativas requer muito tempo e planejamento. Deste modo, Campos (2018) optou por realizar sua pesquisa por ciclos e observou que à medida que avançavam-se os ciclos, a estruturação da atividade como um todo ia-se diminuindo. Portanto, há de se notar que os modelos pedagógicos modificavam-se a medida que os alunos ganhavam mais autonomia. 
Campos (2018), apresenta, também, em uma revisão bibliográfica crítica sobre o ensino por investigação. Nesta consta que vários autores utilizam-na com base construtivista. Entretanto, observando as metodologias dos artigos analisados, o autor concluí que estas ora se aproximam mais do modelo diretivo de ensino; ora lembram uma espécie de apriorismo.

Em suma chegamos à seguinte conclusão: de que não existe univocidade entre as metodologias do ensino por investigação e as bases epistemológicas em que podem ser fundamentadas. Mas, ao que nos parece, ocorre mais por imperícia dos autores do que por proficiência.

\section{Conclusão}

Nas discussões precedentes vimos que o ensino por investigação é diverso, tanto em seu modo de ser especulativo quanto prático. Todavia, após uma síntese da literatura especializada propomos que toda atividade investigativa deve começar por uma situação-problema, não trivial e contextualizada; ter o intento de aproximar a ciência de referência da ciência ensinada nas escolas através de atividades práticas, e, desenvolver a cognição.

Em adição, há de sopesar-se os tipos de problemas que devemos desafiar os alunos da escola básica. Neste sentido, fizemos uma argumentação em prol de que tais problemas sejam do tipo problemas em movimento adequando-se assim, pois, a um só tempo, o aspecto didáticopedagógico (CARVALHO, 2014) e o cognitivo (STERNBERG; STERNBERG, 2016). Consequentemente, naquela altura do texto fizemos a seguinte delimitação do ensino por investigação em segunda aproximação; qual seja: que é uma abordagem didática que modela o ensino das ciências por meio de atividades práticas subjacentes à atividade do cientista, usando-se, por sua vez, problemas (em movimento) contextualizados com soluções bem conhecidas, pelo professor. 
Conforme exposto pomos o ensino por investigação sobre três bases epistemológicas em que os diferentes modelos pedagógicos podem ser realizados utilizando-se da metodologia que convém ao professor. Ressaltamos que existe univocidade entre a base epistemológica e o modelo de ensino, mas, não há, entre àquelas e as metodologias do ensino por investigação. Isto significa que uma mesma metodologia pode ser praticada a diferentes bases epistemológicas.

Logo, podemos realizar atividades de laboratório aberto de acordo com modelo diretivo fazendo uma investigação guiada. Mas, para tanto, há de se ter o controle teórico sobre as possibilidades de atividades investigativas que convém à escola básica. Afinal, como argumenta Clark, Kirschner e Sweller (2012), o professor, independentemente do modelo pedagógico que dispensa para com seus alunos pode, perfeitamente, utilizar de projetos, de discussões, apropriar-se de conhecimentos prévios, entre outros meios.

No entanto, no modelo construtivista estes mecanismos - em um processo dialético de colaboração com o aluno - servem para que o professor conduza-os, pelo melhor caminho, à aprendizagem científica. Adversamente, no modelo diretivo, projeto e discussão não servem para reconstruir conhecimento, mas sim, para verificá-los ou vivenciá-los como preferem alguns.

Em suma, reafirmamos a tese de que a pluralidade de modos de ser do ensino por investigação é um fator a favor e não contra o professor. Mais que se posicionar ideologicamente ante algum modelo pedagógico em especial, vale mais harmonizá-los, ou, até mesmo, diversificar nossa prática pedagógica utilizando-se de todos eles. Com isto, aumentamos nosso potencial de tornar as aulas menos monótonas e conquistar a atenção dos nossos alunos.

\section{Referências}

ABBAGnANO, N. Dicionário de Filosofia. São Paulo: Martins Fontes, 1999. 
ABD-EL-KHALICK, F. et al. Inquiry in science education: International perspectives. Science education, v. 88, n. 3, p. $397-419,2004$.

BACON, F. Novum Organun. In: Os pensadores. [S.l.]: Abril Cultural, 1988.

BARROW, L. H. A brief history of inquiry: From Dewey to standards. Journal of Science Teacher Education, v. 17, n. 3, p. 265 - 278, 2006.

BECKER, F. A origem do conhecimento e a aprendizagem escolar. Porto Alegre: Artmed, 2003.

CAMPOS, J. G. Desenvolvendo o pensamento abstrato no ensino de física por investigação. 2018. Tese (Doutorado) - Escola Normal Superior, Universidade do Estado do Amazonas, Manaus.

CARVALHO, A. M. P. de (org). Termodinâmica: um ensino por investigação. $1^{\mathrm{a}} \mathrm{ed}$. São Paulo: Livraria da Física, 2014.

CASTAÑON, G. A. O que é construtivismo? Caderno de História e Filosofia da Ciência, v. 1, n. 4, p. $209-242,2015$.

CLARK RICHARD E.; KIRSCHNER, P. A.; SWELLER, J. Putting students on the path to learning the case for fully guided instruction: the case for fully guided instruction. American Educator, v. 36, n. 1, p. 6 - 11, 2012.

CRATO, N. O eduquês em discurso directo: uma crítica da pedagogia romântica e construtivista. $11^{\text {a }}$ ed. Lisboa: Gradiva, 2010.

FERREIRA, L. H.; HARTWIG, D. R.; OLIVEIRA, R. C. de. Ensino experimental de química: uma abordagem investigativa contextualizada. Química Nova na Escola, São Paulo, v. 32, n. 2, p. 101 - 106, 2010.

GASPAR, A. Atividades experimentais no ensino de Física: uma nova visão baseada na teoria de Vigotski. $1^{a}$ ed. São Paulo: Livraria da Física, 2014.

HESSEN, J. Teoria do conhecimento. São Paulo: Martins Fontes, 2000.

HUME, D. Investigação sobre o entendimento humano. In: Os pensadores. $3^{\mathrm{a}} \mathrm{ed}$. São Paulo: Abril Cultural, 1984.

KANARI, Z.; MILLAR, R. Reasoning from data: How students collect and interpret data in science investigations. Journal of research in science teaching, Wiley Online Library, v. 41, n. 7, p. $748-769,2004$.

KANT, I. Crítica da razão pura. In: Os pensadores. São Paulo: Abril, 1983.

KANT, I. Crítica da razão pura. São Paulo: Fundação Calouste Goubenkian, 1994. 
KASSEBOEHMER, A. C.; FERREIRA, L. H. Elaboração de hipóteses em atividades investigativas em aulas teóricas de química por estudantes de ensino médio. Química nova na escola, São Paulo, v. 35, n. 3, p. 158 - 165, 2013.

NCR. National science education standards. [S.l.]: National Academies Press, 2000.

NUSSENZVEIG, H. M. Curso de física básica: Mecânica. Porto Alegre: Editora Blucher, 2013. v. 1.

RODRIGUES, B. A.; BORGES, A. T. O ensino de ciências por investigação: reconstrução histórica. Anais do XI Encontro de Pesquisa em Ensino de Física, 2008, Florianópolis, p. $1-12$.

SANTOS, J. C. F. dos. Aprendizagem significativa: modalidades de aprendizagem e o papel do professor. $5^{\mathrm{a}}$ ed. Porto Alegre: Mediação, 2013.

SASSERON, L. H. Alfabetização científica, ensino por investigação e argumentação: relações entre ciências da natureza e escola. Ensaio Pesquisa em Educação em Ciências, Belo Horizonte, v. 17, n. spe, p. 49 - 67, 2015.

STERNBERG, R. J.; STERNBERG, K. Psicologia cognitiva. 2a ed. São Paulo: CENGAGE Learning, 2016.

TERRIBILE, M. de A. A relação entre a crítica de Jean Piaget às epistemologias clássicas e a explicação do processo de produção de novidade. Schème, Marília, v. 11, n. 1, p. $4-21,2019$.

TRÓPIA, G. Percursos históricos de ensinar ciências através de atividades investigativas. Ensaio Pesquisa em Educação em Ciências, Belo Horizonte, v. 13, n. 1, p. $121-138,2011$.

WILLINGHAM, D. T. Por que os alunos não gostam da escola? Respostas da ciência cognitiva para tornar a sala de aula mais atrativa e efetiva. $1^{\mathrm{a}}$ ed. Porto Alegre: Artmed, 2011.

ZÔMPERO, A. F.; LABURÚ, C. E. Atividades investigativas no ensino de ciências: aspectos históricos e diferentes abordagens. Ensaio Pesquisa em Educação em Ciências, Belo Horizonte, v. 13, n. 3, p. 67 - 80, 2011. 